\title{
Tasadenoturev-infected Allogeneic Bone Marrow-derived Mesenchymal Stem Cells
}

\author{
National Cancer Institute
}

\section{Source}

National Cancer Institute. Tasadenoturev-infected Allogeneic Bone Marrow-derived

Mesenchymal Stem Cells. NCI Thesaurus. Code C159798.

A preparation of bone marrow-derived allogeneic mesenchymal stem cells (MSCS) infected with tasadenoturev (Ad5-DNX-2401), an adenovirus serotype 5 strain that is selectively replication competent in cells defective in the Rb/p16 tumor suppressor pathway, with potential antineoplastic activity. Upon infusion of the tasadenoturevinfected bone marrow-derived MSCs, these cells target and deliver the adenovirus to tumor cells. The oncolytic virus then selectively transfects and replicates in the tumor cells, eventually leading to tumor cell lysis and the release of virus particles and various tumor associated antigens (TAAs). This may induce a systemic immune response against tumor cells expressing these TAAs and further infection and killing of nearby tumor cells by the released viral particles. Ad5-DNX-2401 contains an integ rin binding RGD-4C motif, allowing Coxsackievirus and adenovirus receptor-independent infection of tumor cells, which are often deficient for Coxsackievirus and adenovirus receptors (CARs). As integral components of the late $\mathrm{G} 1$ restriction point, the Rb gene product and p16 are negative regulators of the cell cycle and are often defective in certain cancer types. 